BNL -52621

Formal Report

\title{
VAPORIZATION OF TUNGSTEN-METAL IN STEAM AT HIGH TEMPERATURES
}

by

\author{
G.A. Greene and C.C. Finfrock \\ Brookhaven National Laboratory \\ Upton, New York 11973
}

OCTOBER 2000

ENERGY SCIENCES AND TECHNOLOGY DEPARTMENT

Brookhaven National Laboratory

Brookhaven Science Associates

Upton, Long Island, New York 11973

Under Contract No. DE-AC02-98CH10886 with the

UNITED STATES DEPARTMENT OF ENERGY 
BNL- 52621

UC- 704

G.A. Greene and C.C. Finfrock

Brookhaven National Laboratory

Upton, New York 11973

October 2000

Energy Sciences and Technology Department

Brookhaven National Laboratory

Brookhaven Science Associates

Upton, Long Island, New York 11973

Under Contract No. DE-AC02-98CH10886 with the

UNITED STATES DEPARTMENT OF ENERGY 


\section{DISCLAIMER}

This report was prepared as an account of work sponsored by an agency of the United States Government. Neither the United States Government nor any agency thereof, nor any of their employees, not any of their contractors, subcontractors, or their employees, makes any warranty, express or implied, or assumes any legal liability or responsibility for the accuracy, completeness, or usefulness of any information, apparatus, product, or process disclosed, or represents that its use would not infringe privately owned rights. Reference herein to any specific commercial product, process or service by trade name, trademark, manufacturer, or otherwise, does not necessarily constitute or imply its endorsement, recommendation, or favoring by the United States Government or any agency, contractor, or subcontractor thereof. The views and opinions of authors expressed herein do not necessarily state or reflect those of the United States Government or any agency, contractor or subcontractor thercof.

Printed in the United States of America

Available from

National Technical Information Service

U.S. Department of Commerce

5285 Port Royal Road

Springfield, VA 22161 


\begin{abstract}
The vaporization of tungsten from the APT spallation target dominates the radiological source term for unmitigated target overheating accidents [1]. Chemical reactions of tungsten with steam which persist to tungsten temperatures as low as $800^{\circ} \mathrm{C}$ result in the formation of a hydrated tungsten-oxide which has a high vapor pressure and is readily convected in a flowing atmosphere. This lowtemperature vaporization reaction essentially removes the oxide film that forms on the tungstenmetal surface as soon as it forms, leaving behind a fresh metallic surface for continued oxidation and vaporization.
\end{abstract}

Experiments were conducted to measure the oxidative vaporization rates of tungsten in steam as part of the effort to quantify the APT radiological source term for severe target accidents. Tests were conducted with tungsten rods ( $1 / 8$ inch diameter, six inches long) heated to temperatures from approximately $700^{\circ} \mathrm{C}$ to $1350^{\circ} \mathrm{C}$ in flowing steam which was superheated to $140^{\circ} \mathrm{C}$. A total of 19 experiments was conducted. Fifteen tests were conducted by RF induction heating of single tungsten rods held vertical in a quartz glass retort. Four tests were conducted in a vertically-mounted tube furnace for the low temperature range of the test series. The aerosol which was generated and transported downstream from the tungsten rods was collected by passing the discharged steam through a condenser. This procedure insured total collection of the steam along with the aerosol from the vaporization of the rods.

The results of these experiments revealed a threshold temperature for tungsten vaporization in steam. For the two tests at the lowest temperatures which were tested, approximately $700^{\circ} \mathrm{C}$, the tungsten rods were observed to oxidize without vaporization. The remainder of the tests was conducted over the temperature range of $800^{\circ} \mathrm{C}$ to $1350^{\circ} \mathrm{C}$. In these tests, the rods were found to have lost weight due to vaporization of the tungsten and the missing weight was collected in the downstream condensate system. The aerosol formed a fine white smoke of tungsten-oxide which was visible to the eye as it condensed in the laminar boundary layer of steam which flowed along the surface of the rod. The aerosol continued to flow as a smoke tube downstream of the rod, flowing coaxially along the centerline axis of the quartz glass tube and depositing by impaction along the outside of a bend and at sudden area contractions in the piping.

The vaporization rate data from the 17 experiments which exceeded the vaporization threshold temperature are shown in Figure 5 in the form of vaporization rates $\left(\mathrm{g} / \mathrm{cm}^{2} \mathrm{~s}\right) \mathrm{vs}$. inverse temperature $\left(\mathrm{K}^{-1}\right)$. Two correlations to the present data are presented and compared to a published correlation by Kilpatrick and Lott [7]. The differences are discussed. 


\section{TABLE OF CONTENTS}

$\underline{\text { Page }}$

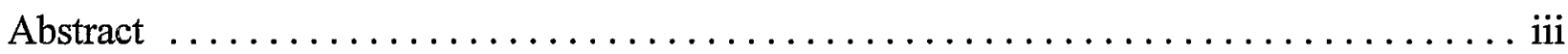

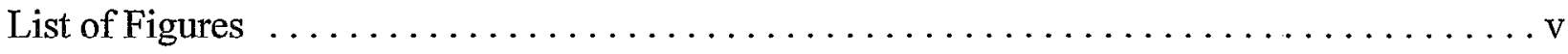

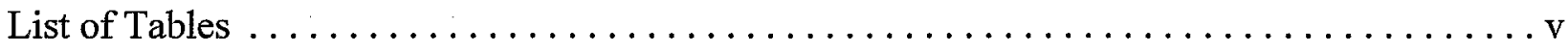

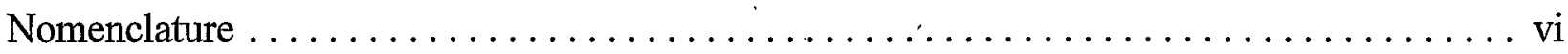

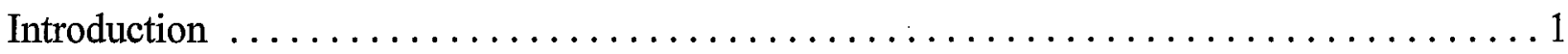

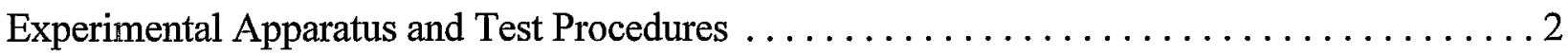

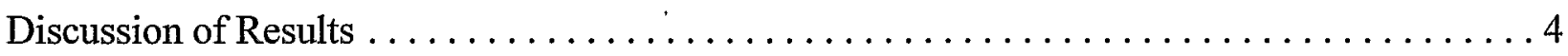

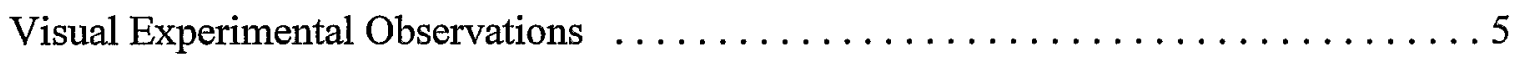

Tungsten-Oxide Aerosol Plate Out, Condensation and Stochiometry $\ldots \ldots \ldots \ldots \ldots 6$

Effects of Hydraulic Diameter and Reynolds Number on Tungsten Vaporization . . . . 8

Onset-of-Vaporization and Vaporization Rate Correlation: $694^{\circ} \mathrm{C}$ to $1337^{\circ} \mathrm{C} \ldots \ldots 11$

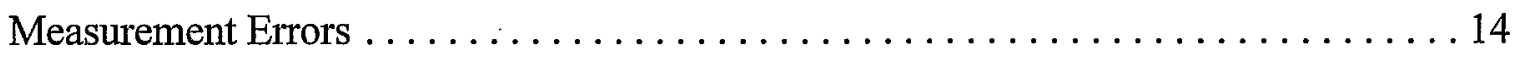

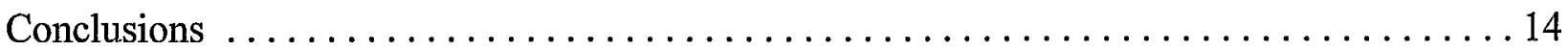

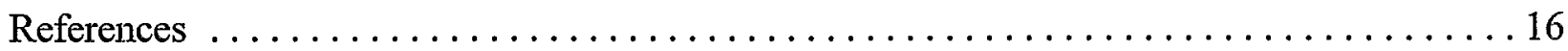




\section{LIST OF FIGURES}

$\underline{\text { Page }}$

Figure $1 \quad$ Schematic of Experimental Facility $\ldots \ldots \ldots \ldots \ldots \ldots \ldots \ldots \ldots \ldots \ldots$

Figure 2 Photographs of RF-Heated Tungsten Rod in the Quartz Glass Retort Inside the RF Coil Showing the White Smoke Tube of Condensed Tungsten-Oxide Aerosols in the Steam Boundary Layer (W-05) . . . . . . . . . . . . . 18

Figure 3 Tungsten-Oxide Recrystallization on the Downstream Cold End of a RF-Heated Tungsten Rod (W-21: Test Parameters in Photograph are Nominal)

Figure 4 Photographs of Tungsten-Oxide Plate Out in Flow Passages Downstream of RF-Heated Test Section (W-02): [A] Plate Out in $140^{\circ}$ Bend, [B] Plate Out in Flow Contractions . . . . . . . . . . . . . . . . . . . . . 20

Figure 5 Tungsten-Metal Vaporization Rates in Steam vs. Temperature $\ldots \ldots \ldots \ldots 21$

\section{LIST OF TABLES}

Table 1 Hydraulic Parameters of Tungsten Vaporization Tests $\ldots \ldots \ldots \ldots \ldots \ldots 22$

Table 2 Distribution of Mass of Tungsten-Oxide Collected During

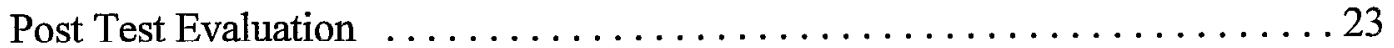

Table 3 Data for Tungsten-Metal Vaporization Rate Correlation $\ldots \ldots \ldots \ldots \ldots 24$

Table 4 Measurement Errors in the Calculation of Tungsten-Metal Vaporization Rate .25 
d diameter, rod or tube

$d_{h} \quad$ hydraulic diameter, $\left(d_{\text {tube }}-d_{\text {rod }}\right)$

D diffusion coefficient

$\mathrm{h}_{\mathrm{M}} \quad$ mass transfer coefficient

$\Delta \mathrm{H} \quad$ heat of vaporization, (cal/g-mol)

$\dot{\mathrm{m}}_{\mathrm{W}}{ }^{\prime \prime} \quad$ tungsten vaporization rate, $\left(\mathrm{g} / \mathrm{cm}^{2} \mathrm{~s}\right)$

$\mathrm{R}$ universal gas constant, $(1.987 \mathrm{cal} / \mathrm{g}-\mathrm{mol} \cdot \mathrm{K})$

Re Reynolds number, $\left(\mathrm{U}_{\text {steam }}\left(\mathrm{d}_{\text {tube }}-\mathrm{d}_{\text {rod }}\right) / v_{\text {steam }}\right)$

$\mathrm{RF} \quad$ radio frequency

Sc Schmidt number, $(v / D)$

Sh Sherwood number, $\left(h_{M} \cdot d_{h} / D\right)$

T temperature

$\mathrm{U}_{\text {steam }}$ average steam velocity

$v_{\text {steam }} \quad$ steam kinematic viscosity 


\section{INTRODUCTION}

The vaporization of tungsten from the APT spallation target has been shown to be the dominant contributor to the radiological source term for unmitigated target overheating accidents [1-4]. Reactions with steam which persist to tungsten temperatures as low as $800^{\circ} \mathrm{C}$ result in the formation of a hydrated tungsten-oxide which has a high vapor pressure and is readily convected in a flowing atmosphere. This low-temperature vaporization reaction essentially removes the oxide scale that forms on the tungsten surface as soon as it forms, leaving behind a fresh metallic surface for continued oxidation and vaporization. Since an oxide scale is not formed, what occurs is a continual process of oxidation and vaporization until either the tungsten temperature decreases below the vaporization threshold and only an oxide crust forms, the gas phase is starved of steam in which case only oxidation will occur, or the tungsten-metal is consumed.

For the APT target overheating accidents in which tungsten vaporization is calculated, the sequence of events which occur is a loss of flow followed by a loss of coolant with a shutdown of the proton beam. Dry out of the target rungs will result in the loss of all axial heat transfer to the engineered heat sink; the only heat transfer mechanism which could remove the decay heat from the irradiated tungsten target cylinders is thermal radiation from the inner most of the nested cylinders radially outward to the outer housing of the target rung, and then by radiative heat transfer to the surrounding blanket modules which may themselves still be cooled by their independent cooling loop. The tungsten target cylinders are nested within each other in a configuration which does not favor thermal radiation as a cooling mechanism. Very high temperatures can occur in the spallation target shortly following a beam shutdown with loss of coolant, approaching or even exceeding $1200^{\circ} \mathrm{C}$, which could result in considerable damage to the target and vaporization of the tungsten.

At these temperatures, the rates of vaporization of tungsten in steam could be very rapid. During test $\mathrm{W}-22$ which was conducted at a temperature of $1335^{\circ} \mathrm{C}$, for example, the tungsten rod was measured to have lost $31 \%$ of its initial mass by vaporization in only 15 minutes. It is not surprising, therefore, that parametric calculations for postulated APT accidents have demonstrated that tungsten release fractions can be quite high under such conditions. Although tungsten vaporization rates can be shown to be extremely rapid, it is still necessary to have an accurate and reliable vaporization model to exercise with accident analysis tools in order to predict the extent of the potential release for a wide range of transients and accidents in the proper geometry and under the appropriate thermal hydraulic conditions. This is required to support decisions on the engineered safety systems to provide the level of protection and the classification of these safety systems in order to comply with on-site and off-site guidelines for radionuclide release, environmental impacts and cxposure of the workers and the public.

The experiments to be reported here were conducted to provide the data necessary to develop the vaporization rate model for accident evaluation to provide the necessary guidance to satisfy radiological guidelines and requirements. 


\section{EXPERIMENTAL APPARATUS AND TEST PROCEDURES}

An overall schematic of the experimental test facility which was assembled to perform these experiments is shown in Figure 1. The test section base was fabricated from type 304 stainless steel and incorporated connections for argon and steam and provided a mounting location for the boronnitride sample holder and fused quartz test section. The base was also equipped with several thermocouples to allow temperature measurements and a trace heating system to prevent steam from. condensing in the base. The base was equipped with a 1.25 inch Cajon compression fitting to facilitate easy installation and removal of the fused quartz test section. Concentric with the compression fitting was a socket that accepted a boron-nitride pedestal that held the sample vertically by the lower end in the induction coil. Fused quartz test sections were fabricated in two internal diameters to allow the investigation of the effects of steam linear velocity (Reynolds number) on the rate of aerosol formation. All fused quartz test sections had the same end fittings to enable a rapid and easy changeover. All glass components downstream of the fused quartz test section used standard tapered ground-glass joints sealed by Teflon joint sleeves.

Surrounding the fused quartz test section was an induction coil wound from 3/16-inch diameter copper refrigeration tubing. The coil consisted of about 20 turns of tubing over the six-inch span of the test sample. The pitch of the coil turns varied from top to bottom and was adjusted to provide a uniform temperature profile on the test samples as verified by the pyrometer. The coil was connected to a Lepel solid state RF power supply which provided RF power to the tungsten test rod and cooling water to the coil. A Pyrex elbow was installed on top of the fused quartz test section. This elbow provided a smooth transition from the vertically-oriented test section to the condensers which angled downward at about $50^{\circ}$ from horizontal. This elbow was also equipped with thermocouples and trace heat to prevent unwanted steam condensation. Two standard tap watercooled laboratory condensers in series provided all the cooling necessary to condense all steam passing through the apparatus. During operation, a condensation front was clearly visible and, even under the highest steam flow conditions, was never more than halfway down the first condenser. A series of tare-weighed beakers was used to collect the effluent from the condensers for further analysis.

Argon was supplied to the apparatus in several locations in order to inert the entire system and also to allow the heat-up of components during startup under conditions of inert gas flow. Argon was supplied to the test section base through an assembly consisting of a flow control valve, a flow meter, a gas heater, and a shutoff valve. This supply was used to inert the base, the test section and the condensers. Another argon supply was connected to the inlct of the steam superheater through a three-way valve, which allowed selection of either steam or argon. This supply allowed the steam superheater to be brought to operating temperature before the introduction of steam, thereby avoiding condensation problems in the superheater on startup. Steam was supplied to the other side of this three-way valve from a low-pressure boiler equipped with an over pressure relief device. Controlling the power to the boiler ultimately controlled the steam flow rate.

Another three-way valve at the exit of the superheater allowed the superheater flow to be directed 
either to the apparatus or to a bypass condenser. When directed to the bypass condenser, the steam flow rate was measured by collecting aliquots of condensate over time and weighing them. After the steam flow rate was properly adjusted, this valve could then be used to direct the steam into the test section.

A computer-controlled scanner, $150 \mathrm{~F}$ thermocouple reference junction and $3455 \mathrm{~A}$ Hewlett Packard digital voltmeter were used to measure temperatures at numerous locations in and on the apparatus. Inputs from numerous type $\mathrm{K}$ thermocouples and the optical pyrometer were connected to the scanner and the data were recorded at prescribed, frequent intervals throughout the test. Using this system, the temperature histories on all of the glassware, the steam inlet and outlet temperatures, the test section base temperatures and the tungsten rod temperature were measured and recorded.

Prior to the conduct of a test, relevant physical parameters of the tungsten sample were measured and recorded on an experimental test form, W-02: Tungsten Aerosol Test Data Sheet, specially prepared for this series of tests. The pre run rod mass, approximately 23 grams, was determined using an analytical balance with a precision of 0.0001 gram. The pre run rod length, nominally 6.0 inches $(15 \mathrm{~cm})$, was measured with a calibrated dial-indicating caliper and recorded with a precision of 0.01 inch. The rod diameter, nominally 0.125 inch $(3 \mathrm{~mm})$, was measured in 12 places spaced at 0.5 -inch intervals along the length of the sample. Pre run variations in individual sample diameters typically were on the order of \pm 0.0002 inch. Post run rod characteristics were also recorded on this data sheet. Actual execution of a test was guided by a detailed test procedure, W-01: Tungsten Aerosol Test Procedure, which provided a checklist-type format of the narrative procedure presented below. These completed sheets have been kept on file as permanent records of the experiments.

The test sample was affixed to the boron-nitride sample holder and the holder installed in the test section base. The fused quartz tube and induction coil were then placed around the sample. Prior to use on an actual sample, the spacing of the induction coil turns was evaluated and adjusted on a dummy sample to provide a uniform temperature distribution. A trace-heated Pyrex elbow was placed on the exit of the quartz tube using a Teflon seal for the tapered ground-glass joint. Following the elbow, two water-cooled condensers with straight internal flow paths were installed in series to provide an overwhelming heat sink to insure complete condensation of the flow. Teflon ground-glass joint seals were also used in the condenser connections. Where appropriate, components of the system were tare-weighed to allow the measurements of the masses of any deposited materials. Adequate supply of argon gas for purging the system components was connected and sufficient water was added to the steam generator.

After a review of the desired test conditions, all supply plumbing and test section glassware that could potentially be exposed to steam were heated to the operating temperature. Care was taken to insure that no condensation of steam occurred in vertical sections of the flow path to avoid refluxing of water back into the reaction zone. A flow of heated argon was established in the test section and also through the steam superheater to allow its adjustment to operating temperature. The steam generator was heated to the operating temperature, and the steam flow was valved through the superheater and then through a third water-cooled condenser. The condensate was then collected 
in timed intervals and weighed to determine the steam flow rate. The power to the steam generator was then adjusted to give the desired steam flow rate.

Once the steam flow rate was properly adjusted, the flow was maintained through the bypass condenser and the RF power supply was energized and the test sample heated in argon to the desired temperature. The tungsten rod temperature was measured with an optical pyrometer focused between the induction coils directly on the tungsten sample. The pyrometer was mounted on a traversing tripod that allowed it to be raised and lowered to evaluate the axial temperature profile of the sample. If necessary, the RF power would be turned off and the induction coil spacing would be adjusted to fine tune the temperature profile of the sample. Once the sample temperature, apparatus temperatures and steam flow rate were all properly adjusted, the test was initiated by simultaneously valving off the argon to the test section and valving in the steam flow. These pre test setups and adjustments could take as long as several hours to stabilize. Tare-weighed beakers were used at the main condenser discharge to collect all the water which was condensed. The condensate water washed down tungsten aerosols which were collected with the water. The collection of condensate was timed to allow calculation of the actual steam flow rate throughout the duration of the experiment. The collected fractions were weighed as collected and then slowly dried with gentle heat and again weighed dry. Using these masses along with the beaker tare mass, the steam flow rates and aerosol generation rates were calculated.

Upon completion of the test, the heated argon was valved back in and the steam was valved out to immediately terminate the vaporization. The RF power supply was turned off and the sample was allowed to cool. After the condensate ceased to run, all support systems were shut down and recovery was begun. Insulation and trace heat were removed from the parts to be disassembled and, with care to preserve any aerosol deposits, the system was disassembled. The sample rod was recovered and it's post test mass and dimensions were recorded.

\section{DISCUSSION OF RESULTS}

The observations and quantitative results of 19 experiments will be discussed in this report. Seventeen of these tests experienced vaporization under the conditions in which they were conducted and these 17 tests are the basis for the empirical tungsten vaporization rate correlations to be presented. The other two tests were conducted at temperatures below the vaporization threshold and oxidized without vaporization. The parameters for each of the 19 tests which were conducted are listed in Table 1. A number of other observations and effects will be discussed, including aerosol plate out and condensation, hydraulic effects and tungsten-oxide stochiometry. Finally, a comparison to some results in the literature will be presented. A comprehensive review of the relevant literature concerning the physical chemistry of tungsten oxidation and vaporization was published recently by Unal, et. al. [5]. In the interest of brevity, this review will not be repeated here; the reader is directed to [5] for more details.

During the conduct of this experimental investigation, a number of experiments were performed with 
Inconel 718 and stainless steel samples to identify their performance at high temperature in steam. Although they oxidized in steam, their rates of oxidation were bounded by their oxidation rates in air at the same temperatures. Also, they were found not to suffer vaporization in steam as did the tungsten samples to be discussed. The rates of oxidation of Inconel 718 at high temperatures in air were reported in a separate study [6] and the reader is referred to that report for more details. The testing of Inconel 718 and stainless steel samples in steam and air will not be discussed further.

\section{Visual Experimental Observations}

The experiments which were performed during this study were all conducted within transparent quartz glass test sections. This enabled visual observations of the test samples during the experiments and the observation of a number of interesting phenomena which will be discussed in this and subsequent sections.

The tests were all conducted under laminar flow conditions in a quartz glass retort which housed the tungsten rods; the flow was laminar in the downstream piping leading to the condenser section of the apparatus as well. The quartz glass retort was aligned in the vertical position with the tungsten rod similarly vertical; steam was introduced to the test section from below and flowed past the test rod vertically into the downstream piping, eventually making a $140^{\circ}$ bend down into the condenser section. Laminar flow was established in these tests, because this was the hydraulic flow regime of interest to the APT target during accident conditions with steam flow through the target due to boil off of the primary coolant. Laminar flow was established by setting the steam flow rate in accordance with pre test calculations, and this was verified by pre test measurements of the condensate flow rate from the boiler which bypassed the heated test section which was being purged by argon gas during the pre test setup and adjustment period prior to the actual vaporization test when the tungsten rods would be exposed to the steam flow. Laminar flow was verified visually during the experiments by observing the aerosol flow from the vaporized tungsten-oxide from the rod. While the tungsten-oxide was hydrated by the steam to tungstic acid vapor, it would enter the steam boundary layer where it would immediately condense back to tungsten-oxide. Photographic records of the aerosol smoke tube flowing along the surface of the RF-heated rod are shown in Figure 2. It would flow through the quartz glass retort as a white smoke tube surrounding the tungsten rod and continue upwards into the transparent downstream piping as a smoke tube along the centerline of the piping. No dispersion or mixing of the aerosol smoke tube was visually observed; the smoke tube was an excellent flow visualization indicator of laminar flow conditions.

Although the tungsten rods were heated by RF induction and uniform temperatures were established along the heated lengths of the rods, the ends of the rods were not heated and were therefore cold compared to the central regions which were undergoing vaporization. Conduction of heat along the rods was not sufficient to keep the ends uniform in temperature with the middle. A similar situation is expected in APT; the rastered proton beam is intended to sweep the middle $18 \mathrm{~cm}$ of the target, leaving both ends unirradiated and therefore colder. In some experiments, it was observed that a rather unusual "top hat" was observed to grow on the downstream end of the rod(s) which consisted of recrystallized tungsten-oxides which deposited on the cold surface from the aerosol stream which 
was passing. These deposits could grow large and were crystalline in appearance and black. An example of such a recrystallized deposit on the downstream tip of the tungsten rod from test W-21 is shown in Figure 3. This observation indicates that deposition and recrystallization of vaporized tungsten-oxides can occur on nearby cold surfaces, phenomena which would tend to retain some of the aerosol which was generated. This recrystallized oxide was counted as mass lost from the rod. No previous mention of this phenomenon was found in the literature and this phenomenon was not further quantified.

During some of the experiments, a $\mathrm{H}_{2}$-like (colorless to faint blue) flame was observed to surround the tungsten rod as it was vaporizing at high temperature in steam. The flame was observed to extend from five to $10 \mathrm{~cm}$ downstream of the end of the tungsten rod in the direction of the condenser. This flame could be intermittent but often was observed to persist for long times during the experiments. One explanation for this flame is combustion of the hydrogen produced by the steam oxidation-vaporization reactions with the high-temperature tungsten rod with oxygen from the boiler (oxygen dissolved in the water in the boiler) or from incomplete reduction of the steam. Regardless, there apparently was some oxygen in the system which resulted in intermittent combustion of some or all of the hydrogen which had been generated. This observation is significant for two reasons. First, if the hydrogen does react in the heated zone as observed in these experiments, then gas-phase analyses to evaluate the vaporization reaction kinetics by hydrogen concentration measurements would lead to incorrect conclusions concerning the chemical reactions of the vaporization process since the concentration of hydrogen would have been reduced by the combustion. This would suggest that the measurement of condensed-phase products would be a more reliable indicator of the chemistry than gas-phase measurements. Secondly, if it could be shown that the hydrogen produced during such conditions in an APT target accident would similarly burn, then accumulations of hydrogen in the APT confinement could be less than stochiometric and hydrogen deflagration or detonation phenomena may not be a concern for APT. Any conclusions concerning possible hydrogen behavior in APT applications are beyond the scope of this report. However, these observations should be considered when such phenomena are considered. No previous mention of this behavior was found in the literature.

\section{Tungsten-Oxide Aerosol Plate Out, Condensation and Stochiometry}

The test apparatus for these experiments was designed and constructed in such a manner so as to facilitate not only visual observations both during and after the experiments, but also the removal and collection of aerosols which were deposited on the walls of the downstream piping and which rained out in the condensate which was collected from the discharge of the condensers. Quantitative mass balance comparisons were made possible as a result of the modular construction of the flow system and the high efficiency of collection of the condensed aerosol particles. Visual observations of the aerosol behavior were possible during the experiments in the bare regions of the test section, the quartz glass retort within the RF coil which contained the tungsten rod and the glass condensers at the discharge end of the flow path. Visual observations in the remainder of the flow system were obscured by the trace heaters and insulation, so only post test observations were possible in these sections. Some of these visual observations as they pertain to the aerosol behavior will be discussed. 
During the experiments, the presence of a smoke tube of condensed aerosol particles flowing around the tungsten rod in the steam boundary layer was clearly evident to the eye through the gaps in the $\mathrm{RF}$ coil which surrounded the quartz glass retort (see Figure 2). The smoke tube of flowing aerosol particles was clear evidence that the tungstic acid vapor $\left(\mathrm{H}_{2} \mathrm{WO}_{4, \mathrm{v}}\right)$ which left the surface of the tungsten rod had condensed in the steam boundary layer adjacent to the heated rod. This smoke tube did not disperse into the flowing dry steam in the quartz retort region but remained along the rod; there was no evidence of the aerosol mixing with the steam flow in the free stream as a result of laminar flow conditions. Careful examination of Figure 2 indicates that the outer boundary of the smoke tube actually delineates the edge of the hydrodynamic boundary layer along the rod; the boundary layer starts at the leading edge of the vaporization front on the upstream surface of the rod and grows in the radial direction as it proceeds downstream as would be predicted by boundary layer theory.

The piping downstream of the RF-heated vaporization section was trace heated and insulated to prevent steam condensation prior to entry into the downward-inclined glass condenser tubes. The steam was dry up to the condensers. There was a practical reason for controlling these conditions, so that water from condensed steam would not reflux back into the heated test section and create a bubbling pool of water around the tungsten rod (this, in fact, did occur during the initial startup tests and considerable effort was required to install trace heaters and temperature controllers to eliminate steam condensation upstream of the condensers). Because the steam remained dry up to the condensers, observations of dry plate out in contractions and bends in the piping were possible.

It was not a primary motivation in the design of this experiment to promote aerosol plate out in the piping. In fact, considerable effort was made to avoid plate out and condensation as just discussed. It was recognized that comparisons of the tungsten-metal mass lost to the tungsten-oxide collected would be facilitated if most or all of the oxide was collected in the condensate. As a result of this consideration, the downstream piping from the RF-heated vaporization section to the condenser section contained a minimal number of contractions in the flow path and only one bend. The contractions in the flow path occurred immediately downstream of the heated test section and were included only to make connections in the piping. The bend in the piping was further downstream and was installed to redirect the upwards flowing dry steam/aerosol mixture into the downwardinclined direction just prior to entry into the condensers. Almost no aerosol was deposited on the surfaces leading into the contractions. What little was deposited was like powder and easily disturbed (see Figure 4b). The single bend in the piping accounted for the majority of the aerosol plate out upstream of the condenser. This bend consisted of a single $140^{\circ}$ turn with a penetration at the top for insertion of a thermocouple into the flow to monitor the temperature of the steam/aerosol mixture. This bend was positioned directly above the heated section in direct line-ofsight with the tungsten rod.

Aerosol deposits in this bend in the flow path were quite thick and yellowish in color. The dead-end penetrations at the top of the bend for the thermocouples became clogged with aerosol deposits much like sediments in a channel. The outside wall of the bend was covered by a thick, solid layer of aerosol while the inside wall remained clean and free of deposits around the bend until the piping 
straightened out. The straight section of piping downstream of the bend was covered with aerosol deposits around the entire perimeter of the tubing; apparently the aerosol suspension flow was sufficiently dispersed by the bend to cause plate out around the entire perimeter of the tubing. This behavior is clearly evident in Figure 4a where the white coating is the deposited aerosol on the inside of the tubing. The pattern of aerosol deposits in the bend was perfectly symmetrical about the vertical profile of the tubing, a result of the laminar conditions in the flow and the absence of mixing. Since there was only one bend in the flow path, the majority of the aerosol continued to be transported with the steam into the condensers which were only inches downstream of the end of the bend. The distribution of tungsten-oxide deposited in the piping and collected in the condensate was measured for nine of the 17 vaporization tests performed. The results of these measurements are listed in Table 2 [Note: The measurements of the oxide mass samples for W-05 and W-08 were compromised during weighing. Mass distribution measurements were not performed for W-21, W$22, \mathrm{~W}-29, \mathrm{~W}-30, \mathrm{~W}-33$ and W-34]. It is evident from Figure 2 that nominally $10 \%$ of the total aerosol mass that was collected after the tests was recovered from the spool piece with the $140^{\circ}$ bend. Additional deposition of aerosols would have occurred if additional bends had been provided for the dry steam/aerosol mixture to navigate.

Analyses of the masses of oxide collected to the masses of metal lost from the tungsten rods due to vaporization for the nine tests listed in Table 2 resulted in an average ratio of oxide mass to metal mass of 1.24 . Assuming $100 \%$ efficient post test oxide collection, the stochiometry of the tungstenoxide was found to be $\mathrm{WO}_{2.7}$, indicating that the oxide which was formed was a mixture of both $\mathrm{WO}_{2}$ and $\mathrm{WO}_{3}$ in the same ratio over the temperature range from $927^{\circ} \mathrm{C}$ to $1298^{\circ} \mathrm{C}$. Data for temperatures above $1298^{\circ} \mathrm{C}$ and temperatures below $927^{\circ} \mathrm{C}$ are not available from these tests. This observation is strong evidence that the chemistry of tungsten oxidation and vaporization is complex and it may prove to be difficult to calculate from a chemical thermodynamic approach [5]. No simple engineering solution may be practical other than the observation that oxides of tungsten formed in steam at temperatures above $800^{\circ} \mathrm{C}$ readily vaporize in steam and condense upon cooling into a fine aerosol.

\section{Effects of Hydraulic Diameter and Reynolds Number on Tungsten Vaporization}

Two parameters of phenomenological interest with respect to their effects upon the rate of vaporization of tungsten-metal in steam are the Reynolds number of the steam flow and the hydraulic diameter of the flow path. Effects of both parameters will be addressed in the discussion which follows.

The mass transfer coefficient in turbulent flow is dependent upon the Reynolds number and Schmidt number as given by the following relationship,

$$
\mathrm{Sh}=\mathrm{h}_{\mathrm{M}} \cdot \mathrm{d}_{\mathrm{h}} / \mathrm{D}=f(\mathrm{Re}, \mathrm{Sc})=\mathrm{C} \cdot \mathrm{Re}^{\mathrm{x}} \cdot \mathrm{Sc}^{\mathrm{y}}
$$

where $\mathrm{C}, \mathrm{x}$ and $\mathrm{y}$ are constants usually derived from empirical data. In laminar flow as in the present experiments, however, the Sherwood number is equal to a constant and not a function of the 
Reynolds number, i.e., $\mathrm{Sh}=\mathrm{K}$, where $\mathrm{K}$ is once again derived from empirical data. In this case, the mass transfer coefficient in laminar flow is a constant, dependent only upon the diffusion coefficient $D$ of the fluid and the hydraulic diameter $d_{h}$ of the channel. There are two sets of experiments in the present data base available for comparison to evaluate the effects of the Reynolds number as manifested through the hydraulic diameter on the tungsten vaporization rate which will be discussed.

Test W-29 was conducted at a temperature of $990^{\circ} \mathrm{C}$ in a $0.4 \mathrm{~cm}$ diameter glass retort $\left(\mathrm{d}_{\mathrm{h}}=0.1 \mathrm{~cm}\right)$ at $\operatorname{Re}=20$; three comparable tests which were conducted in a $2.18 \mathrm{~cm}$ glass retort $\left(\mathrm{d}_{\mathrm{h}}=1.9 \mathrm{~cm}\right)$ at similar temperatures are W-02 $\left(\operatorname{Re}=204, \mathrm{~T}=1016^{\circ} \mathrm{C}\right), \mathrm{W}-03\left(\operatorname{Re}=454, \mathrm{~T}=1014^{\circ} \mathrm{C}\right)$ and W-04 $\left(\operatorname{Re}=670, \mathrm{~T}=1016^{\circ} \mathrm{C}\right)$. The tungsten vaporization rate for $\mathrm{W}-29$ was measured to be $1.07 \times 10^{-5}$ $\mathrm{g} / \mathrm{cm}^{2} \mathrm{~s}$ and, for $\mathrm{W}-02, \mathrm{~W}-03$ and $\mathrm{W}-04$, the average of the tungsten vaporization rates for all three tests was measured to be $1.40 \times 10^{-5} \mathrm{~g} / \mathrm{cm}^{2} \mathrm{~s}$. This is an average variance of about $30 \%$ over a range of hydraulic diameters of 19 and ratios of Reynolds numbers of 10,22 and 30. Not only is this variance in the vaporization rate due to $d_{h}$ between W-29 and W-02/W-03/W-04 small, there is no apparent trend between the last three tests themselves to indicate an effect of steam velocity through the Reynolds number.

Test W-30 was conducted at a temperature of $1113^{\circ} \mathrm{C}$ in a $0.4 \mathrm{~cm}$ diameter glass retort, also with a hydraulic diameter of $0.1 \mathrm{~cm}$ (with the $3 \mathrm{~mm}$ tungsten rod installed) at $\mathrm{Re}=17$; other tests which were conducted in the $2.18 \mathrm{~cm}$ glass retort $\left(\mathrm{d}_{\mathrm{h}}=1.8 \mathrm{~cm}\right)$ at similar temperatures are W-06 $(\mathrm{Re}=449$, $\left.\mathrm{T}=1124^{\circ} \mathrm{C}\right)$ and $\mathrm{W}-16\left(\mathrm{Re}=434, \mathrm{~T}=1124^{\circ} \mathrm{C}\right)$. The tungsten vaporization rate for $\mathrm{W}-30$ was measured to be $4.17 \times 10^{-5} \mathrm{~g} / \mathrm{cm}^{2} \mathrm{~s}$; the tungsten vaporization rates for $\mathrm{W}-06$ and W-16 were measured to be $4.27 \times 10^{-5} \mathrm{~g} / \mathrm{cm}^{2} \mathrm{~s}$ and $5.17 \times 10^{-5} \mathrm{~g} / \mathrm{cm}^{2} \mathrm{~s}$, respectively. The average variance in the tungsten vaporization rates between W-30 and the average of W- $06 / \mathrm{W}-16$ is about $13 \%$, with W-30 and W-06 being nearly identical. The ratio of the hydraulic diameters was 19 and the ratio of the Reynolds numbers was 26 . Once again, no apparent trend due to the Reynolds number is apparent.

The mass transfer rates in these comparisons clearly are insensitive to the hydraulic parameters of the tests through the Reynolds number in laminar flow. Table 3 and Figure 5 indicate that the tungsten vaporization rates are, however, strongly dependent upon the temperatures of the tungsten rods. Although there should be some dependence of the mass transfer rate on the hydraulic diameter in laminar flow, the mass transfer resistance in the gas phase is clearly small in these experiments in comparison to the thermal resistance to mass transfer at the surface of and within the surface of the tungsten rods due to chemical/kinetic effects. The conclusion is that, (a) under laminar flow conditions and (b) with the tungstic acid concentration in the free stream equal to zero, the resistance to mass transfer or vaporization of the tungsten metal is limited by chemical/kinetic effects at the tungsten surface and may be modeled reasonably accurately as a function of the tungsten temperature only. If the experimental conditions were altered such that the resistance to mass transfer in the gas phase was to become significant with respect to the chemical/kinetic mass transfer resistance, both effects would have to be considered in the framework of an integral model. The present experiments only address the chemical/kinetic or temperature-dependent mass transfer resistance to tungsten vaporization but may be combined with an analytical methodology which accounts for gas-phase resistance effects for general application. The data from the present experiments, by eliminating free 
stream mass transfer effects, possibly represent an upper limit to the tungsten vaporization rate.

The effects of steam velocity and hydraulic diameter through the Reynolds number have just been discussed and their effects on the tungsten vaporization rates have been shown to be insignificant in comparison to chemical/kinetic effects at the surface of the tungsten rods which are strongly dependent upon the tungsten temperature. Another independent effect of the hydraulic diameter was manifest in these experiments which is not Reynolds number dependent but which may have a significant effect upon the tungsten vaporization rate. In the tests which were performed in the 2.18 $\mathrm{cm}$ quartz glass tube, the ratio of the hydraulic diameter of the flow channel to the diameter of the tungsten rod was 6.3 ; the same ratio was only 0.25 in the tests in the $0.4 \mathrm{~cm}$ quartz glass tube, a factor of 25 difference. An independent effect of the channel diameter was observed in those tests which used the $0.4 \mathrm{~cm}$ quartz glass tube which will be discussed below. It was observed in the experiments and previously discussed that the hydrated tungsten-oxide vapor $\left(\mathrm{H}_{2} \mathrm{WO}_{4}\right)$ which left the surface of the tungsten rod rapidly condensed (or dehydrated) upon entering the cold steam boundary layer $\left(\sim 150^{\circ} \mathrm{C}\right)$ and gave the appearance of a flowing smoke tube along the surface of and surrounding the heated rod (see Figure 2). This behavior was a spectacular manifestation of aerosol condensation and laminar boundary layer flow under the experimental conditions imposed. The aerosol flowed downstream and did not plate out until encountering a bend or contraction in the flow path, as shown in Figures $4 a, b$. The $2.18 \mathrm{~cm}$ diameter quartz glass retort surrounding the RF-heated tungsten rod remained clear and transparent for the duration of the tests.

The aerosol exhibited quite different behavior, however, in those tests which utilized the $0.4 \mathrm{~cm}$ diameter quartz glass retort. The aerosol condensed in the cold, flowing steam as before. However, due to the reduced hydraulic diameter of the flow channel past the heated tungsten rod, the flowing smoke tube of condensed tungsten-oxide aerosol particles was able to interact immediately with the "cold" surface of the nearby quartz glass which did not couple to the RF field and was heated only by thermal radiation from the tungsten rod. The lateral distance from the surface of the tungsten rod to the inner surface of the $0.4 \mathrm{~cm}$ diameter quartz glass retort was only $0.5 \mathrm{~mm}$. During a test, it was observed that aerosols would deposit on the inside of the quartz glass tube in the heated zone of the $\mathrm{RF}$ coil and, as time progressed, the deposits could obscure the heated rod from the pyrometer. Two tests were successfully conducted in the $0.4 \mathrm{~cm}$ quartz glass retort and were reported as W-29 and W-30. The aerosols which were deposited on the inside surface of the glass neither obscured the pyrometer nor interfered with the steam flow. One test which was not reported, W-32, was conducted at $1180^{\circ} \mathrm{C}\left(190^{\circ} \mathrm{C}\right.$ hotter than W-29 and $67^{\circ} \mathrm{C}$ hotter than W-30). Because of the higher temperature in this test, the tungsten vaporization rate in this test was greater than in W-29 and W30. There was significant deposition on the inside of the quartz glass retort during W-32 which not only obscured the tungsten rod from the pyrometer rendering the temperature data unreliable, but also obstructed the flow of steam through the test section. Eventually, the flow of steam was entirely blocked and the experiment was terminated. The surface of the quartz glass retort was sufficiently "cold" to promote plate out and eventually block the channel entirely. A somewhat similar effect was presented in Figure 3 where it was shown that the tungstic acid vapor condensed and formed a substantial structure upon encountering the "cold" end of the heated tungsten rod. Such deposits within channels with cold surfaces should be expected and it is quite likely that complete blockages 
could form by deposition, especially in geometries with parallel flow paths which would allow the steam to bypass without pressure build up.

\section{Onset-of-Vaporization and Vaporization Rate Correlation: $694^{\circ} \mathrm{C}$ to $1337^{\circ} \mathrm{C}$}

A total of 19 experiments is reported in Table 3; seventeen of these experiments experienced vaporization and two of the tests experienced oxidation without vaporization (W-35 and W-36). These tests and the tungsten vaporization rate correlation which were developed will be discussed.

It is of interest to be able to predict the rates of vaporization of tungsten-metal in steam at high temperatures. Of equal interest is the ability to predict the temperature at which vaporization will begin, otherwise known as the onset-of-vaporization temperature. Experiments were performed over a wide range of temperatures in this investigation, from $694^{\circ} \mathrm{C}$ to $1337^{\circ} \mathrm{C}$. Most of the experiments were conducted at high temperatures with RF heating in order to measure the temperaturedependence of the rates of vaporization of tungsten in steam. Several tests were conducted, however, to narrow in on the range of temperature in which the reactions of tungsten with steam changed from just oxidation to oxidation and vaporization. Due to the low temperatures of the onset-ofvaporization tests, these four tests were conducted in a laboratory furnace with thermocouple measurements instead of in a RF coil with pyrometer measurements, because the temperatures were below the temperature range of the pyrometer. At the lowest end of the temperature range were tests $\mathrm{W}-35$ at $694^{\circ} \mathrm{C}$ and $\mathrm{W}-36$ at $696^{\circ} \mathrm{C}$. The hydraulic conditions of these two tests are listed in Table 1 and the results of these tests are listed in Table 3 . In Table 3, it is indicated that the tungsten-metal rods from both tests exhibited a mass gain over the duration of the tests, which ranged from 11 hours for W-35 to 14 hours for W-36. W-35 gained $30 \mathrm{mg}$ and W-36 gained $11 \mathrm{mg}$. There was no visual evidence of vaporization during either test, and there was no oxide collected on the downstream piping or in the steam condensate. It was concluded from these tests that the vaporization threshold temperature was greater than $700^{\circ} \mathrm{C}$.

Since the tests in this investigation were conducted in temperature increments of approximately $100^{\circ} \mathrm{C}$, the next temperature tested was $800^{\circ} \mathrm{C}$. Two tests were conducted at this temperature, W-33 at $803^{\circ} \mathrm{C}$ and $\mathrm{W}-34$ at $804^{\circ} \mathrm{C}$. Due to the slow chemical reaction rates in these tests, they were conducted for 15 and 17 hours, respectively. Vaporization was evident in these tests, both visually and from inspection of the deposits on the downstream piping and in the condensate, and both tungsten rods exhibited a substantial mass loss of approximately 0.3 to $0.5 \mathrm{~g}$. Both tests were subsequently included in the vaporization rate analysis to be discussed. However, on the basis of these four tests, it was concluded that the onset-of-vaporization threshold for tungsten-metal in steam was between $700^{\circ} \mathrm{C}$ and $800^{\circ} \mathrm{C}$. At temperatures below $700^{\circ} \mathrm{C}$, the tungsten would oxidize without vaporization. The oxide would remain on the rod unless mechanically removed and the oxide was not mobilized with the flowing steam. At temperatures above $800^{\circ} \mathrm{C}$, the tungsten would oxidize and vaporize. The rates of vaporization are dictated by the tungsten temperatures. The vapor would diffuse from the tungsten surface and condense in the boundary layer of flowing steam. The aerosol would be easily transported with the steam; some would plate out in contractions and bends in the downstream piping and the remainder would remain with the condensate as the steam condensed in 
the condensers. These experiments indicate that the onset-of-vaporization temperature is in the temperature range $700-800^{\circ} \mathrm{C}$, suggesting also that the tungstic acid vapor $\left(\mathrm{H}_{2} \mathrm{WO}_{4, \mathrm{v}}\right)$ which leaves the metal surface would condense or dehydrate in the same temperature range. If the steam were hotter than the vaporization threshold temperature, the tungstic acid which formed would remain in the vapor phase until colder regions were encountered.

Of the 19 experiments which were conducted during this investigation, 17 experienced vaporization and were used to construct the tungsten-metal vaporization model to be presented [Note: The numbering of the tests as shown in the tables indicates gaps in the sequence of the reported data. This is not to be interpreted to mean that data were selectively omitted from reporting. The gaps indicate that other tests with Inconel and steel samples were conducted along with the tungsten tests which are presented here. The numbering scheme of the tests was sequential without regard to the metal being investigated. The data from all the tungsten tests which were successful and only tungsten tests are reported here]. The form of the vaporization rate correlation which is assumed is as follows, $\dot{\mathrm{m}}_{\mathrm{W}}{ }^{\prime \prime}=f(\Delta \mathrm{H}, \mathrm{R}, \mathrm{T})$, where $\dot{\mathrm{m}}_{\mathrm{W}}{ }^{\prime \prime}$ is the rate of tungsten-metal vaporized per unit surface area $\left(\mathrm{g} / \mathrm{cm}^{2} \mathrm{~s}\right), \mathrm{R}$ is the universal gas constant $(1.987 \mathrm{cal} / \mathrm{g}-\mathrm{mol} \cdot \mathrm{K}), \Delta \mathrm{H}$ is the heat of vaporization $(\mathrm{cal} / \mathrm{g}-\mathrm{mol})$ and $\mathrm{T}$ is the tungsten surface temperature $(\mathrm{K})$. The average tungsten vaporization rate $\dot{\mathrm{m}}_{\mathrm{W}}$ " was calculated using the tungsten mass loss $(\Delta \mathrm{M})$, heated rod length $(\ell)$ and diameter $(\mathrm{d})$, and run duration (t) from Table 3 (columns 7, 5, 6 and 4, respectively) as shown below in Eq.(2).

$$
\dot{\mathrm{m}}_{\mathrm{W}}{ }^{\prime \prime}\left(\mathrm{g} / \mathrm{cm}^{2} \mathrm{~s}\right)=\Delta \mathrm{M} /(\pi \mathrm{d} \ell \mathrm{t})
$$

The length is not the overall rod length but only the length of the heated zone of the rod which was clearly evident upon inspection and accurately measurable. The rod diameter used in the correlation was the average of the pre test rod diameter and the post test rod diameter. The heat of vaporization, $\Delta \mathrm{H}$, was treated two ways in developing the correlation to the experimental data. The correlation was first calculated using a value of $\Delta \mathrm{H}$ suggested in the literature [7] which had substantial corroboration from other investigators; $\Delta \mathrm{H}=48.9 \mathrm{kcal} / \mathrm{g}$-mol. This approach permitted direct comparison of the results reported in [7] to the present results as will be shown. The second approach was to allow $\Delta \mathrm{H}$ to be treated as an independent variable to be determined by the mathematical form of the resulting correlation. As will be seen, both approaches resulted in remarkably close agreement.

The correlation which was sought was of the form $\dot{\mathrm{m}}_{\mathrm{W}}{ }^{\prime \prime}=\mathrm{A} \cdot \exp [-\Delta \mathrm{H} / \mathrm{RT}]$ where $\mathrm{A}$ is a constant and the other variables have been defined. The resulting correlations are given below,

and

$$
\dot{\mathrm{m}}_{\mathrm{w}}{ }^{\prime \prime}\left(\mathrm{g} / \mathrm{cm}^{2} \mathrm{~s}\right)=2611 \cdot \exp [-48900 / \mathrm{RT}]
$$

$$
\dot{\mathrm{m}}_{\mathrm{W}}^{\prime \prime}\left(\mathrm{g} / \mathrm{cm}^{2} \mathrm{~s}\right)=1433 \cdot \exp [-47230 / \mathrm{RT}]
$$

where, in the first case, the heat of vaporization was assumed from [7] to be $48.9 \mathrm{kcal} / \mathrm{g}-\mathrm{mol}$ and, in the second case, the heat of vaporization was derived by correlation to be $47.23 \mathrm{kcal} / \mathrm{g}-\mathrm{mol}$. Both heats of vaporization are very close and there is no basis to prefer one to the other. Both correlations 
are shown in Figure 5 along with the 17 data points from which the correlations were generated. The axes of Figure 5 are typical of an Arrhenius-type relationship as just shown. Note that both curves are extremely close and nearly touch each of the data points. It should also be pointed out that there is no distinction between the data from the $2.18 \mathrm{~cm}$ retort and those from the $0.4 \mathrm{~cm}$ retort. No apparent trend which could be attributed to Reynolds number is apparent in the data; the parameter which dominates the rate of vaporization of tungsten-metal in steam is the temperature of the metal. Either of these correlations is recommended for the calculation of the rates of vaporization of tungsten-metal in steam with the provision that the onset-of-vaporization threshold temperature has been shown to be in the range $700-800^{\circ} \mathrm{C}$ which the user must stipulate.

For the purpose of critically evaluating the present experimental data and the correlations which were derived from the data, comparisons to data in the literature would be useful. Kilpatrick and Lott [7] reported data from experiments which were conducted with tungsten rods in steam over the temperature range $1050^{\circ} \mathrm{C}$ to $1700^{\circ} \mathrm{C}$. They correlated their data in two temperature ranges, $1050^{\circ} \mathrm{C}$ to $1450^{\circ} \mathrm{C}$ and $1450^{\circ} \mathrm{C}$ to $1700^{\circ} \mathrm{C}$, due to the different functional dependencies of the vaporization rates with temperature apparent in their data. The data correlation from [7] for their low-temperature range $\left(1050^{\circ} \mathrm{C}\right.$ to $\left.1450^{\circ} \mathrm{C}\right)$ is appropriate for comparison to the present data which covered the temperature range $803^{\circ} \mathrm{C}$ to $1337^{\circ} \mathrm{C}$. Although the hydrodynamic flow regime of the steam was not reported in [7], the comparisons of the data to be discussed as well as other asscssments of the experimental apparatus used in [7] suggest that the steam flow regime was laminar. The present data did not extend to the range of their high-temperature correlation; therefore, comparisons of the present data to the Kilpatrick-Lott correlation for the $1450^{\circ} \mathrm{C}-1700^{\circ} \mathrm{C}$ temperature range cannot be made. The low-temperature tungsten vaporization correlation from [7] is of the same form as Eqs. $(3 \mathrm{a}, \mathrm{b})$. However, there is an error in the coefficient of the correlation from [7] of a factor of $10^{3}$ and the units are in terms of gram-atoms and minutes. After making the correction and conversions suggested above, the Kilpatrick-Lott correlation for tungsten-metal vaporization in steam becomes,

$$
\dot{\mathrm{m}}_{\mathrm{W}}{ }^{\prime \prime}\left(\mathrm{g} / \mathrm{cm}^{2} \mathrm{~s}\right)=5172 \cdot \exp [-48900 / \mathrm{RT}]
$$

The only difference between the corrected Kilpatrick-Lott correlation (Eq. (4)) and the correlation of the present experimental data (Eq. (3a)) is in the relative magnitudes of the correlation coefficients. Recall that the heat of vaporization for tungsten from [7] was used in the derivation of Eq. (3a) to facilitate comparison. It is interesting to note that the coefficient of Eq. (4) is precisely a factor of two greater than the coefficient of Eq. (3a) to within $1 \%$. The present authors conducted an exhaustive search to retrieve the original data from [7] in order to resolve this discrepancy without success. The unsubstantiated conclusion of the authors is that there was an error in the formulation of Eq. (4), possibly in the calculation of the surface area of the test rods, which resulted in the under calculation of the surface area by a factor of two. Such an error would shift the Kilpatrick-Lott correlation (Eq. (4)) higher than the present data correlation (Eq. (3a)) by exactly a factor of two.

Examination of Eq. (3b) and Eq. (4) is useful to compare the heat of vaporization derived by correlation of the data of [7] to the heat of vaporization derived by correlation of the present data. The heat of vaporization derived in [7] is $48.9 \mathrm{kcal} / \mathrm{g}-\mathrm{mol}$; when the data from the present 
investigation were correlated with the heat of vaporization determined as an independent variable, the heat of vaporization so determined was $47.23 \mathrm{kcal} / \mathrm{g}-\mathrm{mol}$. This value is well within the range quoted in the literature and about $3 \%$ different from the value in [7]. This slight variation could well be the result of the different temperature ranges covered by the two investigations $\left(1050^{\circ} \mathrm{C}\right.$ to $1450^{\circ} \mathrm{C}$ for [7] and $803^{\circ} \mathrm{C}$ to $1337^{\circ} \mathrm{C}$ for the present investigation). This comparison indicates that both the present data and the data from [7] are consistent in so far as the thermodynamic trends of the data as a function of the tungsten temperature; graphically, this means that the two correlations plot as parallel lines as shown in Figure 5. This further suggests that the underlying reason for the factor of two difference in the coefficients of Eq. (3a) and Eq. (4) is unrelated to differences in thermal or thermodynamic conditions or effects in the two investigations; the factor of two difference in the two correlations is most likely the result of the unresolved mathematical inconsistency previously suggested. The correlations of the present experimental data (Eqs. $(3 a, b)$ ) are recommended for the calculation of tungsten-metal vaporization in flowing steam in laminar flow.

\section{Measurement Errors}

The uncertainties in the measurements of the time-averaged tungsten mass vaporization rates $\left(\dot{\mathrm{m}}_{\mathrm{W}}{ }^{\prime \prime}\right)$ for the experiments reported are functions of the tungsten masses vaporized $(\Delta M)$, the heated rod lengths ( () , the rod diameters (d), and the durations of the experiments (t). These variables, their nominal values, measurement uncertainties and fractional errors are listed in Table 4. It is evident that the uncertainty in $\dot{\mathrm{m}}_{\mathrm{W}}{ }_{\mathrm{W}}$ is dominated by the uncertainties in rod length ( $\ell$ ), rod diameter (d) and duration of experiment $(t)$. As stated in Table 3, the rod diameter is the average of pre and post test measurements. This error is dominated by the variability of the post test diameters; while the pre test diameter measurements had an uncertainty of $\pm 0.0002 \mathrm{inch}$, the variability of the post test diameters was \pm 0.002 inch, an order of magnitude greater. Therefore, the uncertainty in the rod diameter is listed in Table 4 as \pm 0.002 inch. Due to the nature of the experiments, the mass vaporized, which is the difference between the initial and final rod masses, could be measured to very high precision and accuracy. The fractional error in the absolute temperature was small due to the high temperatures of the experiments. The overall measurement uncertainty of the tungsten vaporization rate, $\dot{\mathrm{m}}_{\mathrm{W}}$ ", is thus estimated on average to be approximately $3.4 \%$.

\section{CONCLUSIONS}

The of vaporization of pure tungsten in steam were measured over a range of temperature applicable to APT accident analyses. The following results were obtained:

1. It was demonstrated that tungsten can vaporize in steam at temperatures in excess of $800^{\circ} \mathrm{C}$. The vapor immediately condensed to a fine white aerosol as it left the metal surface and was convected away in the steam boundary layer. 
2. At $700^{\circ} \mathrm{C}$, the tungsten oxidized in steam but was not hydrated into the vapor phase. The oxide formed a crust on the metal surface; no aerosol was generated and the tungsten-oxide was not mobilized.

3. On the order of $10 \%$ of the aerosol stream plated out on cold surfaces in these experiments as it passed through contractions in the flow path or was deposited on the outside of a bend in the piping as it rounded a turn in the flow path, even under laminar flow conditions. The remainder of the aerosol was collected in the condenser with the condensing steam, resulting in $100 \%$ collection efficiency of the aerosol.

4. The mechanism of aerosol retention in the condenser is believed to be heterogenous condensation of steam on the tungsten-oxide particles. The steam preferentially condensed on the aerosol particles which served as nucleation sites, causing the particles to grow and settle under gravity or impact on the walls due to inertia.

5. The stochiometry of the collected aerosol was calculated to be $\mathrm{WO}_{\mathrm{x}}$ where $\mathrm{x}=2.7$. This suggests that both $\mathrm{WO}_{2}$ and $\mathrm{WO}_{3}$ are hydrated to the vapor phase in the form of tungstic acid. Since the chemistry of tungsten vaporization is so complex, this observation suggests that it may be more useful to estimate tungsten vaporization from empirical data than from physical chemistry principles.

6. The experiments reported in this study were conducted with pure tungsten rods in a $100 \%$ steam atmosphere with the free stream vapor concentration equal to zero $\left(\mathrm{C}_{\mathrm{H} 2 \mathrm{wox}}=0\right)$. The resulting data represent the maximum thermodynamic vaporization rates achievable. The correlations which were developed for maximum tungsten vaporization rates are as follows,

or

$$
\dot{\mathrm{m}}_{\mathrm{W}}{ }^{\prime \prime}\left(\mathrm{g} / \mathrm{cm}^{2} \mathrm{~s}\right)=2611 \cdot \exp [-48900 / \mathrm{RT}]
$$

$$
\dot{\mathrm{m}}_{\mathrm{W}}{ }^{\prime \prime}\left(\mathrm{g} / \mathrm{cm}^{2} \mathrm{~s}\right)=1433 \cdot \exp [-47230 / \mathrm{RT}]
$$

both of which predict exactly one-half the vaporization rate of the Kilpatrick-Lott model [7].

7. Accident consequence calculations based upon the predictions of the tungsten vaporization rate model resulted in a decision to clad the APT tungsten target in Inconel 718 [6]. 


\section{REFERENCES}

1. Miller, L. A., G. A. Greene and B. E. Boyack, "Accelerator Production of Tritium Programmatic Environmental Impact Statement Input Submittal," SAND 93-2094 (1996).

2. "Final Programmatic Environmental Impact Statement for Tritium Supply and Recycling," DOE/EIS-0161 (1995).

3. "Preliminary Safety Analysis Report," Accelerator Production of Tritium, PPO-POO-G-PSA-X-00001, Los Alamos National Laboratory (1998).

4. "APT Conceptual Design Report," Accelerator Production of Tritium, LA-UR-97-1329, Los Alamos National Laboratory (1997).

5. Unal, C., W. R. Bohl and K. Pasamehmetoglu, "Reaction of Tungsten in Steam Flow at High Temperatures," International Topical Meeting on Nuclear Reactor Thermal Hydraulics, NURETH-9, Paper No. 218, San Francisco, CA (1999).

6. Greene, G. A. and C. C. Finfrock, "Oxidation of Inconel 718 in Air at Temperatures From $973 \mathrm{~K}$ to $1620 \mathrm{~K}$," BNL Formal Report (1999).

7. Kilpatrick, M. and S. K. Lott, "Reaction of Flowing Steam With Refractory Metals III. Tungsten $\left(1000^{\circ} \mathrm{C}-1700^{\circ} \mathrm{C}\right)$, " J. Electrochemical Soc., 113 (1), pp. 17-18 (1966). 


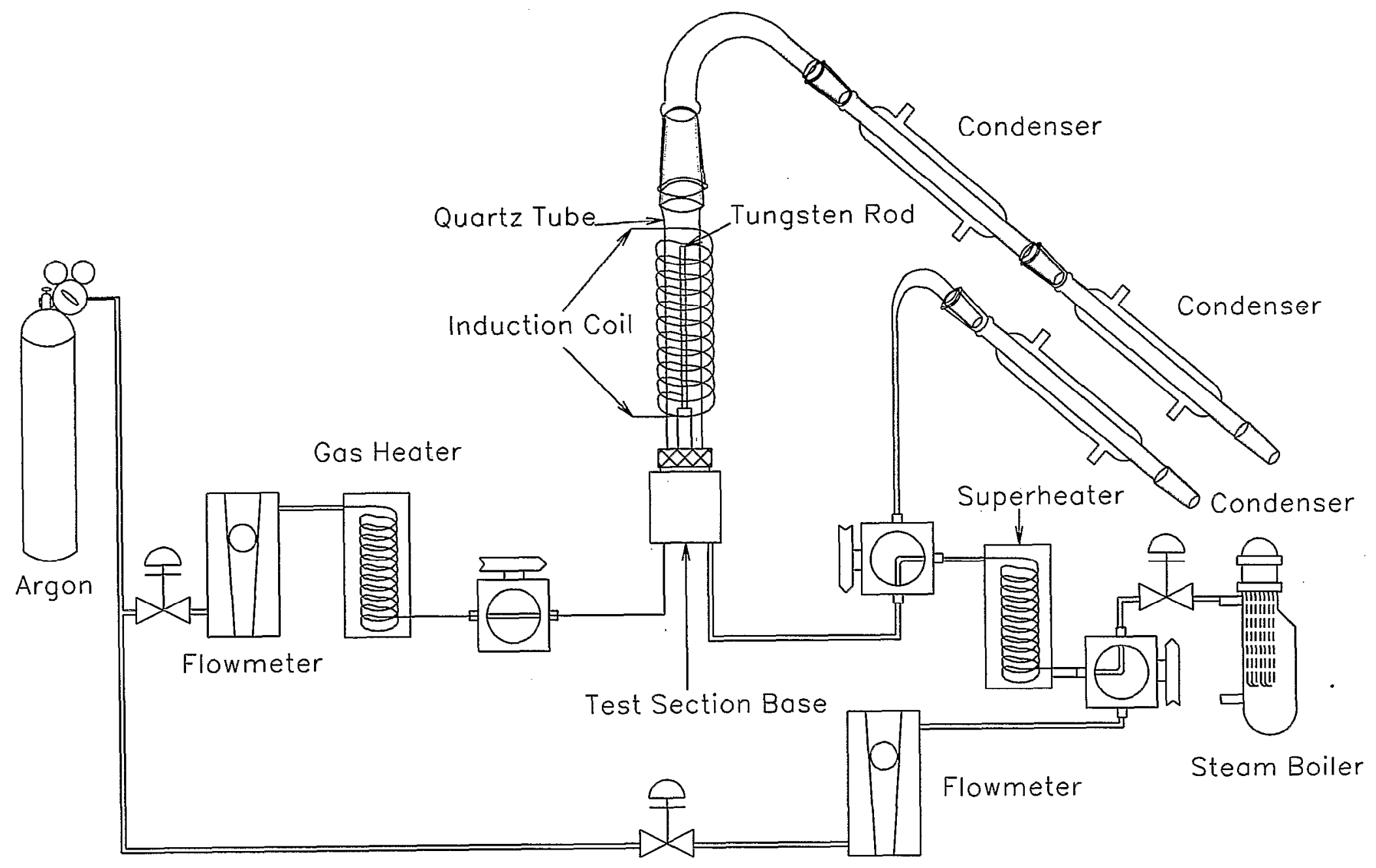

Figure 1. Schematic of experimental facility. 

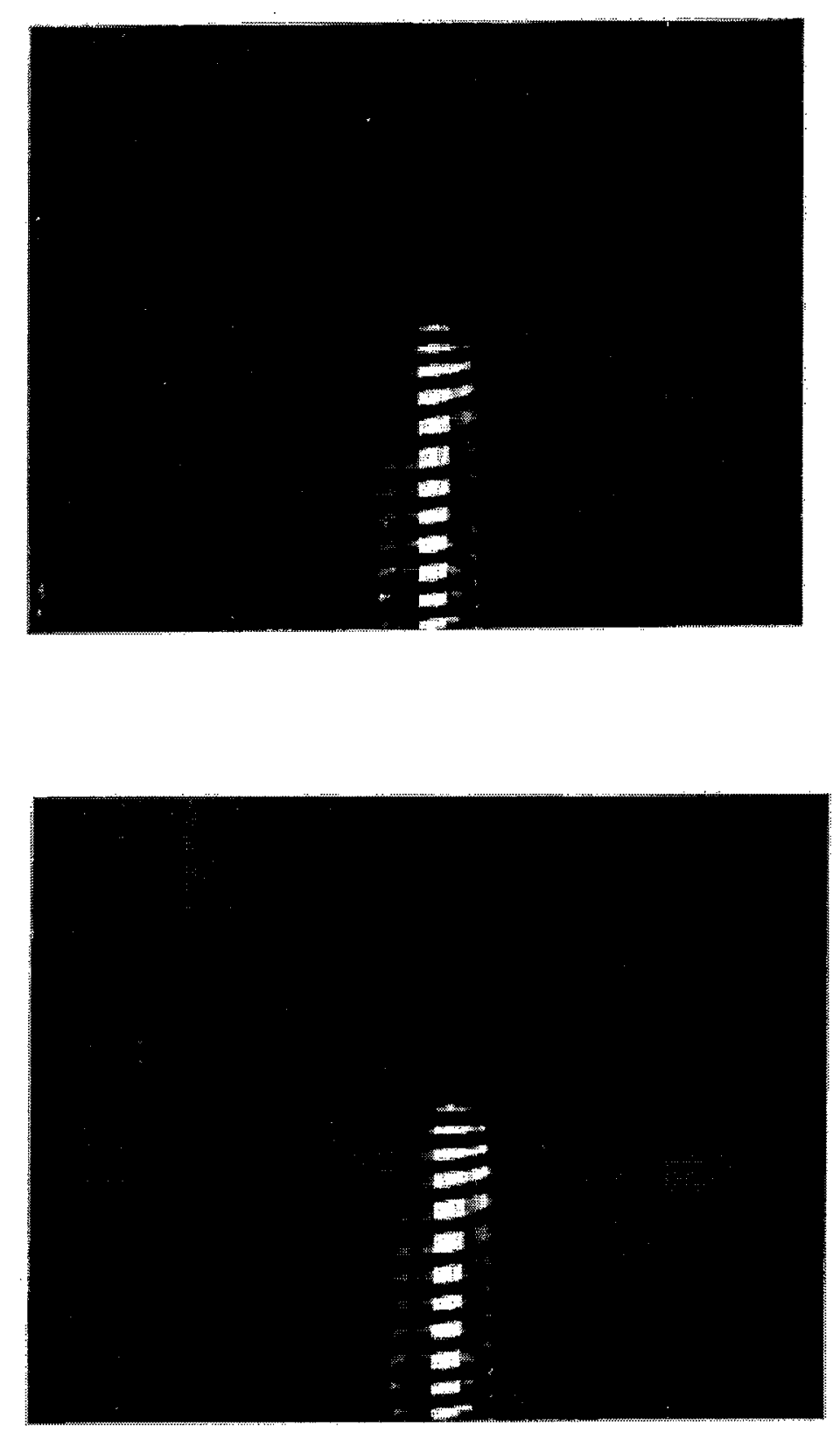

Figure 2. Photographs of RF-heated tungsten rod in the quartz glass retort inside the RF coil showing the white smoke tube of condensed tungsten-oxide aerosols in the steam boundary layer (W-05). 

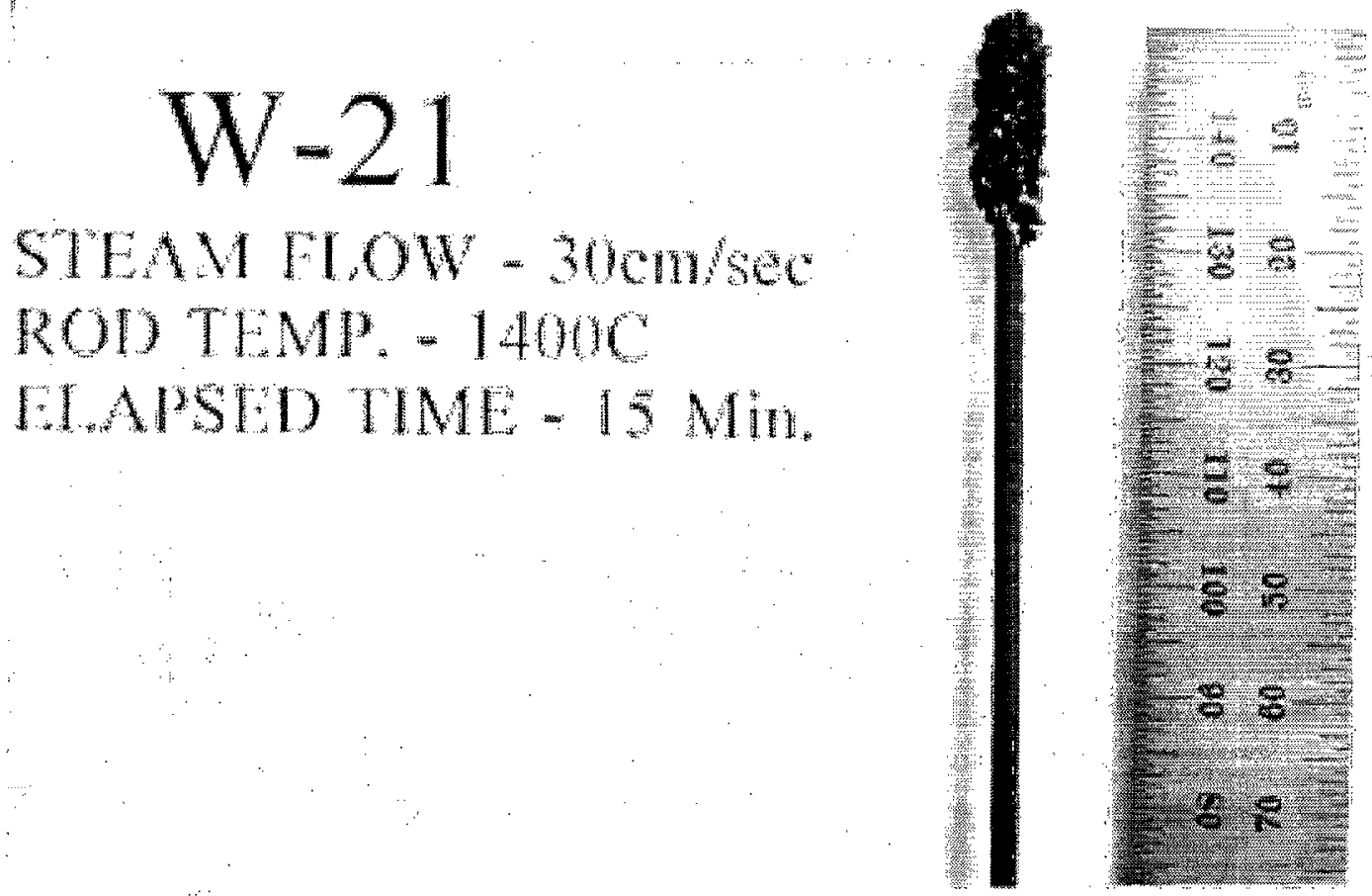

Figure 3. Tungsten-oxide recrystallization on the downstream cold end of a RF-heated tungsten rod (W-21: test parameters in photograph are nominal). 
[A]

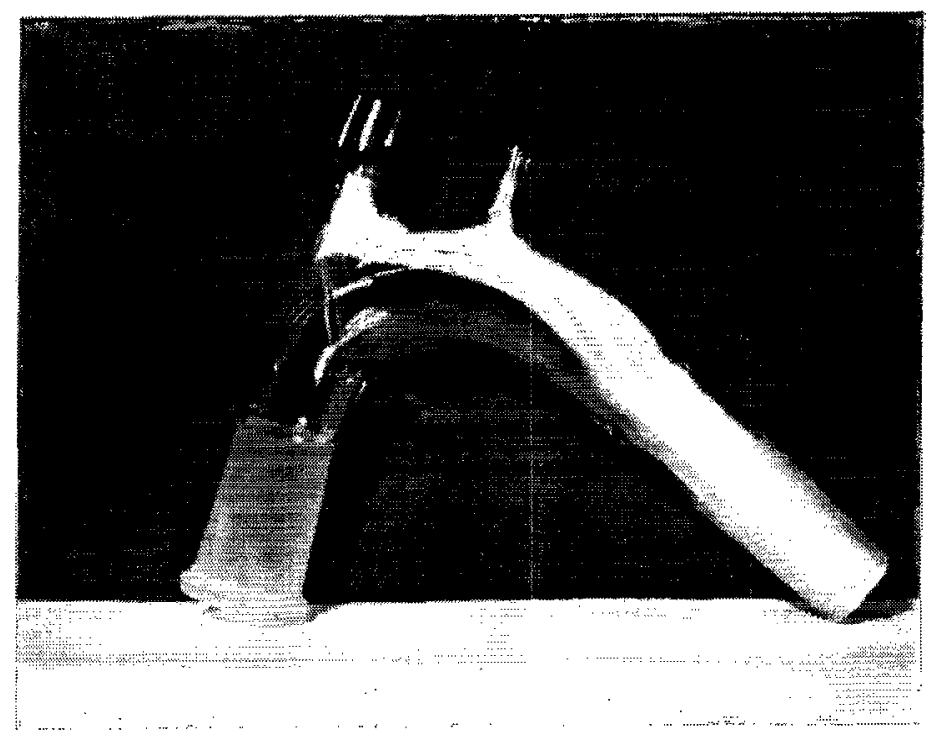

[B]

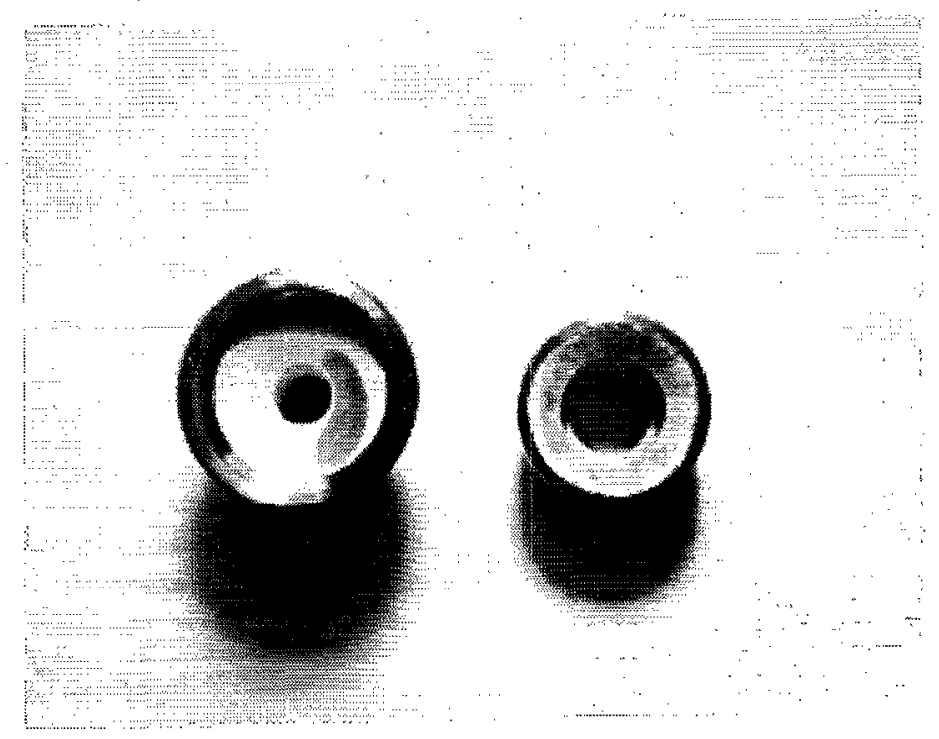

Figurc 4. Photographs of tungsten-oxide plate out in flow passages downstream of RF-heated test section (W-02): [A] plate out in $140^{\circ}$ bend, [B] plate out in flow contractions. 


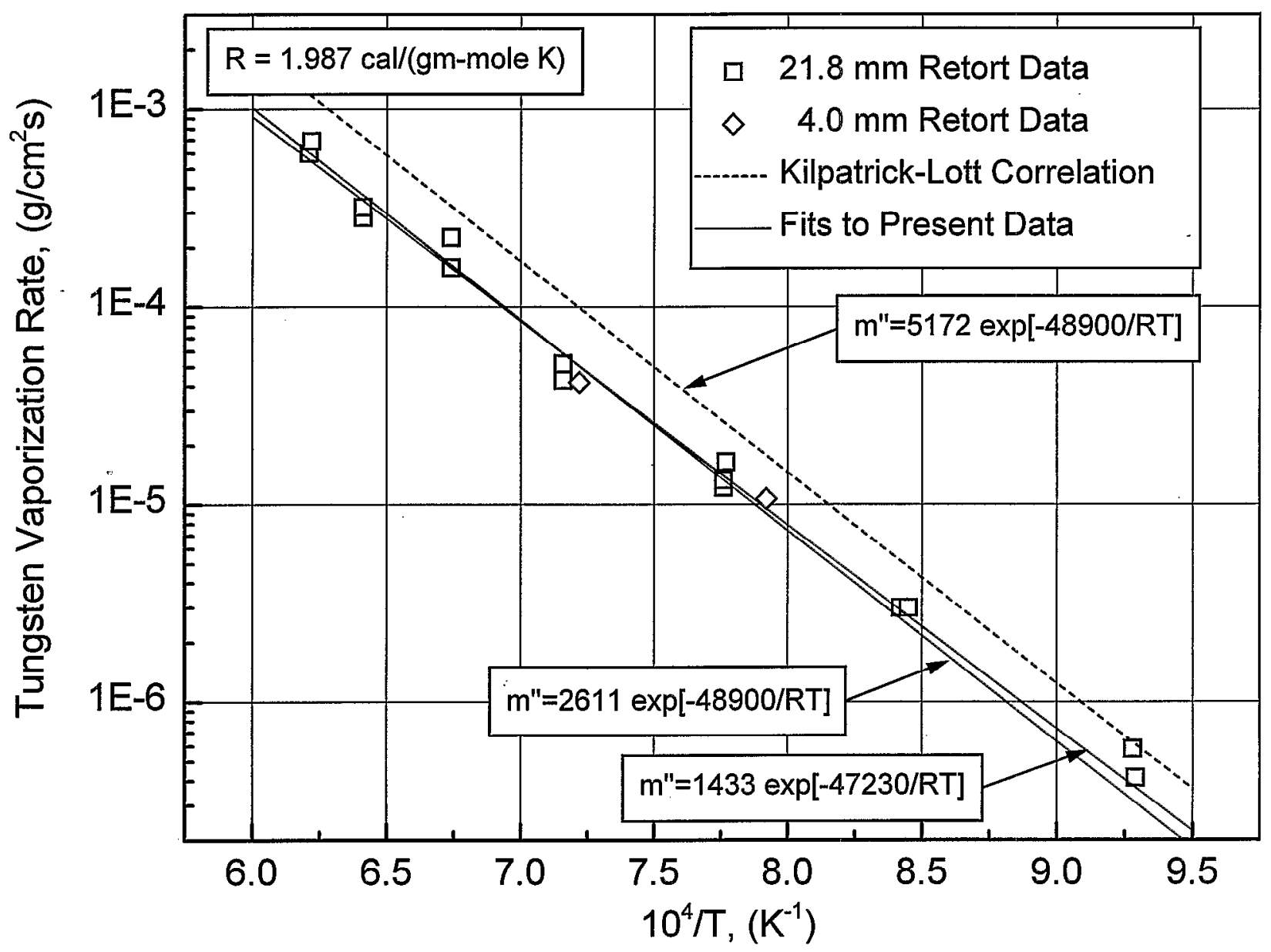

Figure 5. Tungsten-metal vaporization rates in steam vs. temperature. 
Table 1

Hydraulic Parameters of Tungsten Vaporization Tests

\begin{tabular}{|c|c|c|c|c|c|c|}
\hline Run & $\begin{array}{c}\text { W-Rod } \\
\text { Temp } \\
\left({ }^{\circ} \mathrm{C}\right)\end{array}$ & $\begin{array}{c}\text { Steam Inlet } \\
\text { Temperature } \\
\left({ }^{\circ} \mathrm{C}\right)\end{array}$ & $\begin{array}{c}\text { Diameter, } \\
\text { Flow Tube } \\
(\mathrm{cm})\end{array}$ & $\begin{array}{c}\text { Steam Mass } \\
\text { Flux } \\
(\mathrm{g} / \mathrm{min})\end{array}$ & $\begin{array}{c}\text { Steam } \\
\text { Velocity } \\
(\mathrm{cm} / \mathrm{s})\end{array}$ & $\begin{array}{c}\text { Steam } \\
\text { Reynolds } \\
\text { Number }{ }^{[2]}\end{array}$ \\
\hline W-02 & 1016 & 136 & 2.18 & 3.502 & 26.8 & 204 \\
\hline W-03 & 1014 & 136 & 2.18 & 7.648 & 58.6 & 454 \\
\hline W-04 & 1016 & 136 & 2.18 & 11.292 & 86.4 & 670 \\
\hline W-05 & 1211 & 146 & 2.18 & 3.431 & 26.6 & 206 \\
\hline W-06 & 1124 & 144 & 2.18 & 7.488 & 57.9 & 449 \\
\hline W-08 & 911 & 143 & 2.18 & 7.479 & 57.8 & 448 \\
\hline W-14 & 1210 & 146 & 2.18 & 3.579 & 27.8 & 216 \\
\hline W-15 & 1288 & 147 & 2.18 & 3.624 & 28.1 & 218 \\
\hline W-16 & 1124 & 146 & 2.18 & 7.227 & 56.0 & 434 \\
\hline W-17 & 915 & 140 & 2.18 & 7.360 & 56.7 & 440 \\
\hline W-21 & 1337 & 142 & 2.18 & 2.971 & 22.9 & 178 \\
\hline W-22 & 1335 & 140 & 2.18 & 3.460 & 26.6 & 206 \\
\hline W-23 & 1287 & 141 & 2.18 & 3.353 & 25.9 & 201 \\
\hline W-29 & 990 & 147 & 0.40 & 0.079 & 48.5 & 20.0 \\
\hline W-30 & 1113 & 128 & 0.40 & 0.070 & 42.1 & 17.4 \\
\hline W-33 & 803 & 140 & 2.18 & 2.671 & 20.5 & 159 \\
\hline W-34 & 804 & 142 & 2.18 & 3.750 & 28.9 & 224 \\
\hline W-35 & 694 & 141 & 2.18 & 5.104 & 39.3 & 305 \\
\hline W-36 & 696 & 141 & 2.18 & 3.330 & 25.7 & 199 \\
\hline
\end{tabular}

1. All stock tungsten rods were nominally $3 \mathrm{~mm}$ diameter $(0.125 \mathrm{inch})$ and $15 \mathrm{~cm}$ long $(6.0 \mathrm{inch})$.

2. Reynolds number $=\mathrm{U}_{\text {steam }} \cdot\left(\mathrm{d}_{\text {tube }}-\mathrm{d}_{\text {rod }}\right) / v_{\text {steam }}$ where $v_{\text {steam }}=0.2425 \mathrm{~cm}^{2} / \mathrm{s}$. 
Table 2

Distribution of Mass of Tungsten-Oxide Collected During Post Test Evaluation ${ }^{[1]}$

\begin{tabular}{|c|c|c|c|c|c|}
\hline Run & $\begin{array}{c}\text { W-Metal } \\
\text { Loss (g) }\end{array}$ & $\begin{array}{c}\text { W-Oxide } \\
\text { Plate Out(g) }\end{array}$ & $\begin{array}{c}\text { W-Oxide in } \\
\text { Condensate (g) }\end{array}$ & $\begin{array}{c}\text { Total Oxide } \\
\text { Collected (g) }\end{array}$ & $\begin{array}{c}\text { Mass Ratio, } \\
\text { Oxide/Metal }\end{array}$ \\
\hline W-02 & 0.5305 & 0.0800 & 0.5707 & 0.6507 & 1.23 \\
\hline W-03 & 0.7019 & 0.0865 & 0.7854 & 0.8719 & 1.24 \\
\hline W-04 & 0.5216 & 0.0072 & 0.6433 & 0.6505 & 1.25 \\
\hline W-06 & 1.9908 & 0.2114 & 2.2514 & 2.4628 & 1.24 \\
\hline W-14 & 3.2971 & 0.5360 & 3.4744 & 4.0104 & 1.22 \\
\hline W-15 & 6.8831 & 0.5057 & 7.9908 & 8.4965 & 1.23 \\
\hline W-16 & 3.2899 & 0.4372 & 3.5955 & 4.0327 & 1.23 \\
\hline W-17 & 0.4437 & 0.0679 & 0.4874 & 0.5553 & 1.25 \\
\hline W-23 ${ }^{[2]}$ & 3.7758 & ---- & --- & 4.6696 & 1.24 \\
\hline
\end{tabular}

1. These tests cover the temperature range $915^{\circ} \mathrm{C}(\mathrm{W}-17)$ to $1288^{\circ} \mathrm{C}(\mathrm{W}-15)$.

2. The oxide deposits collected from $\mathrm{W}-23$ were inadvertently combined during collection. 
Table 3

Data for Tungsten-Metal Vaporization Rate Correlation

\begin{tabular}{|c|c|c|c|c|c|c|c|}
\hline Run & $\begin{array}{c}\text { W-Rod } \\
\text { Temp } \\
\left({ }^{\circ} \mathrm{C}\right)\end{array}$ & $\begin{array}{c}\text { Steam } \\
\text { Temp } \\
\left({ }^{\circ} \mathrm{C}\right)\end{array}$ & $\begin{array}{c}\text { Run } \\
\text { Duration } \\
\text { (minute) }\end{array}$ & $\begin{array}{c}\text { Length, } \\
\text { Heated } \\
\text { Zone (inch) }\end{array}$ & $\begin{array}{c}\text { Heated Rod } \\
\text { Dimeter }^{[3]} \\
(\mathrm{inch})\end{array}$ & $\begin{array}{c}\text { W-Mass } \\
\text { Loss }{ }^{[1]} \\
(\mathrm{g})\end{array}$ & $\begin{array}{c}\text { Vaporization } \\
\text { Rate } \\
\left(\mathrm{g} / \mathrm{cm}^{2} \mathrm{~s}\right)\end{array}$ \\
\hline W-02 & 1016 & 136 & 60.0 & 4.42 & 0.1240 & 0.53048 & $1.328 \times 10^{-5}$ \\
\hline W-03 & 1014 & 136 & 60.0 & 4.76 & 0.1235 & 0.70186 & $1.638 \times 10^{-5}$ \\
\hline W-04 & 1016 & 136 & 60.0 & 4.70 & 0.1245 & 0.52155 & $1.222 \times 10^{-5}$ \\
\hline W-05 & 1211 & 146 & 51.5 & 5.23 & 0.1110 & 8.16504 & $2.246 \times 10^{-4}$ \\
\hline W-06 & 1124 & 144 & 60.0 & 5.23 & 0.1222 & 1.99083 & $4.270 \times 10^{-5}$ \\
\hline W-08 & 911 & 143 & 240.0 & 4.50 & 0.1243 & 0.48814 & $2.991 \times 10^{-6}$ \\
\hline W-14 & 1210 & 146 & 30.0 & 4.76 & 0.1201 & 3.29709 & $1.582 \times 10^{-4}$ \\
\hline W-15 & 1288 & 147 & 30.0 & 5.27 & 0.1121 & 6.88308 & $3.194 \times 10^{-4}$ \\
\hline W-16 & 1124 & 146 & 90.0 & 4.85 & 0.1199 & 3.28994 & $5.172 \times 10^{-5}$ \\
\hline W-17 & 915 & 140 & 240.0 & 4.11 & 0.1240 & 0.44368 & $2.984 \times 10^{-6}$ \\
\hline W-21 & 1337 & 142 & 15.0 & 5.30 & 0.1138 & 6.57723 & $5.984 \times 10^{-4}$ \\
\hline W-22 & 1335 & 140 & 15.0 & 5.12 & 0.1126 & 7.2376 & $6.886 \times 10^{-4}$ \\
\hline W-23 & 1287 & 141 & 19.7 & 4.72 & 0.1181 & 3.77582 & $2.831 \times 10^{-4}$ \\
\hline W-29 & 990 & 147 & 120.0 & 5.37 & 0.1233 & 1.03289 & $1.069 \times 10^{-5}$ \\
\hline W-30 & 1113 & 128 & 30.0 & 4.69 & 0.1238 & 0.88371 & $4.172 \times 10^{-5}$ \\
\hline W-33 & 803 & 140 & 935.0 & 5.22 & 0.1267 & 0.31040 & $4.124 \times 10^{-7}$ \\
\hline W-34 & 804 & 142 & 1025.0 & 5.26 & 0.1249 & 0.47350 & $5.786 \times 10^{-7}$ \\
\hline W-35 & 694 & 141 & 665.0 & 5.31 & 0.1266 & $-0.0299^{[2]}$ & $-5.502 \times 10^{-8}$ \\
\hline W-36 & 696 & 141 & 835.0 & 5.33 & 0.1258 & $-0.0113{ }^{[2]}$ & $-1.661 \times 10^{-8}$ \\
\hline
\end{tabular}

1. On average, the initial mass of each tungsten rod was $23.0 \mathrm{gm}$.

2. Negative mass loss indicates that only oxidation was occurring, the rod gained mass.

3. The column "Diameter, Heated Rod (inch)" is the average of the initial and final rod diameters. 
Table 4

Measurement Errors in the Calculation of Tungsten-Metal Vaporization Rate

\begin{tabular}{|c|c|c|c|}
\hline Independent Variable & Nominal Values & Measurement Uncertainty & $\begin{array}{c}\text { Fractional } \\
\text { Error }\end{array}$ \\
\hline $\begin{array}{l}\text { Mass of rod, } M \\
\text { Rod length, } \ell \\
\text { Rod diameter } \\
\text { Mass vaporized, } \Delta \mathrm{M} \\
\text { Time, } \mathrm{t} \\
\text { Rod temperature, } \mathrm{T}\end{array}$ & $\begin{array}{c}23 \mathrm{~g} \\
10 \mathrm{~cm} \\
3 \mathrm{~mm} \\
0.5 \text { to } 8.0 \mathrm{~g}^{[3]} \\
500 \text { to } 10^{4} \mathrm{~s}^{[3]} \\
1300 \mathrm{~K}\end{array}$ & $\begin{array}{c} \pm 0.1 \mathrm{mg} \\
\pm 2.5 \mathrm{~mm}(=0.1 \mathrm{inch}) \\
\pm 0.05 \mathrm{~mm}(=0.002 \mathrm{inch})^{[1]} \\
\pm 0.2 \mathrm{mg}^{\left[{ }^{[1]}\right.} \\
\pm 10 \mathrm{~s} \\
\pm 5 \mathrm{~K}\end{array}$ & $\begin{array}{c}4.4 \mathrm{E}-6 \\
0.025 \\
0.020 \\
0.0002 \\
0.010 \\
0.004\end{array}$ \\
\hline $\mathrm{W}$ vaporization rate, $\dot{\mathrm{m}}_{\mathrm{W}}{ }^{\prime \prime}$ & 4E-7 to $7 \mathrm{E}-4 \mathrm{~g} / \mathrm{cm}^{2} \mathrm{~s}$ & RMS & 0.034 \\
\hline
\end{tabular}

1. Rod length and diameter were measured in inches, converted to metric units.

2. Rod diameter is average of both pre and post test diameter measurements.

3. Nominal value for mass vaporized, $\Delta \mathrm{M}$, in uncertainty calculation is $1 \mathrm{~g}$.

4. Uncertainty in mass vaporized is twice the mass uncertainty.

5. Nominal value for time, $t$, in uncertainty calculation is $1000 \mathrm{~s}$. 